Textures and Microstructures, 1996, Vol. 26-27, pp. 385-412

Reprints available directly from the publisher.

Photocopying permitted by license only
() 1996 OPA (Overseas Publishers Association) Amsterdam B.V. Published in The Netherlands under license by Gordon and Breach Science

Publishers SA Printed in Malaysia

\title{
THE EFFECT OF PARTICLES ON RECRYSTALLISATION TEXTURES AND MICROSTRUCTURES
}

\author{
HANS ERIK VATNE*, STEINAR BENUM**, OLE DAALAND** \\ and ERIK NES*** \\ *Hydro Aluminium, R\&D Centre Sunndals $\phi r a, N-6600$ Sunndals $\phi r a$, Norway \\ **Hydro Aluminium, R\&D Centre Karmøy, N-4265 Håvik, Norway \\ ***The Norwegian Institute of Technology, Department of Metallurgy, \\ N-7034 Trondheim, Norway
}

(Received 28 December 1995)

\begin{abstract}
The way in which large and small particles influence on recrystallised grain size and texture is considered with special emphasis on the processing of aluminium. It is well known that large particles might induce nucleation of recrystallised grains, while finely dispersed small particles will exert a pinning force on boundary movement. It the present paper, these two effects of particles will be discussed in detail. The discussion will to some extent be in an overview form, but also new ideas and recent experimental results will be presented. These include cases where strong effects are caused by small precipitated particles.
\end{abstract}

KEY WORDS: Aluminium, recrystallisation, particle stimulated nucleation, particle pinning

\section{INTRODUCTION}

There are two main effects of particles on recrystallisation: (i) large, undeformable particles may generate nucleation sites for recrystallised grains and (ii) small particles will represent a retarding force on the migration of sub-boundaries as well as high angle boundaries. The latter means that not only the growth of viable nuclei will be retarded, but also nucleation since this includes migration of low angle boundaries. In the present paper the effects of both large particles and small precipitates on recrystallisation textures and microstructures will be considered. This treatment will mainly be of a review type, however, new ideas for: (i) particle stimulated nucleation (PSN) from particles located on grain boundaries and (ii) the effect of precipitation on the evolution of recrystallisation textures will be presented.

Dedication: This paper is dedicated to the memory of Professor Dr. Dr. h. c. William Hsun Hu of the University of Pittburgh who died on February 1, 1995. He made large contributions to the study of recrystallisation and will be greatly missed by his many friends and colleagues. 


\section{PARTICLE STIMULATED NUCLEATION OF RECRYSTALLISED GRAINS}

The presence of large, hard particles during deformation of a softer metal matrix will induce strong deformation gradients which are associated with both microstructural refinement and lattice orientation gradients. Particle stimulated nucleation (PSN) is the event by which a recrystallised grain is nucleated in such a deformation zone. Many industrial alloys, particularly those of iron and aluminium, contain large, second-phase particles. This means that PSN most likely is an import nucleation mechanism in many engineering materials, and PSN has been observed in many alloy systems, including those of aluminium, iron, copper and nickel. In most cases only one grain is found to nucleate at any particle, although there is evidence that multiple nucleation might occur at very large particles. This is clearly seen in Figure 1a which is one of the first micrographs to demonstrate PSN. An example of an in situ annealing sequence is given in Figure $1 \mathrm{~b}-\mathrm{c}$.

\subsection{The mechanism of PSN}

Early HVEM work by Humphreys (1977), Herbst and Huber (1978) and Bay and Hansen (1979) revealed the following characteristics of PSN: (i) Recrystallised grains originate at pre-existing subgrains within the deformation zone, but not necessarily at the particle surface. (ii) Nucleation occurs by rapid sub-boundary migration. (iii) The growth of the grain may stagnate when the deformation zone has been consumed. Based on these observations, three criteria for a successful PSN event can be stated: (i) The presence of a deformation zone with sufficiently large lattice rotations. The formation of such a zone will depend on the deformation temperature because the effective recovery reactions at high deformation temperatures will strongly retard the evolution of deformation zones. (ii) The formation of a nucleus within the zone by sub-boundary migration. (iii) Growth beyond of the deformation zone. After the deformation zone is consumed, the potential nucleus must have reached a critical size and acquired a high angle boundary misorientation (i.e. high mobility) in order to be able to grow into the surrounding matrix. Humphreys (1979) has shown that the latter is a restrictive criterion which in most cases determines the efficiency of the PSN mechanism.

The condition for a successful PSN event to occur, i.e. growth of recrystallisation beyond the deformation zone, can also be formulated mathematically based on the wellknown Gibbs-Thompson criterion. This states that a potential new grain has to reach a critical size $\delta_{c}$ in order to acquire a growth capacity, where $\delta_{c}$ is given by:

$$
\delta_{c}=\frac{4 \gamma}{P_{D}^{M}}
$$

Here, $\mathrm{P}_{\mathrm{D}}^{\mathrm{M}}$ is the stored energy in the matrix adjacent to the deformation zone and $\gamma$ is the specific grain boundary energy between the nucleus and its surroundings. For purposes of modelling it is interesting to note that the width of the deformation zone appears to scale with the particle diameter as shown by Humphreys $(1977,1979)$. If one single subgrain consumes all of the deformation zone, it will under this assumption obtain a size $3 \eta$, where $\eta$ is the particle size. Based on this, the growth criterion of Eq. (1) can be reformulated as follows: 


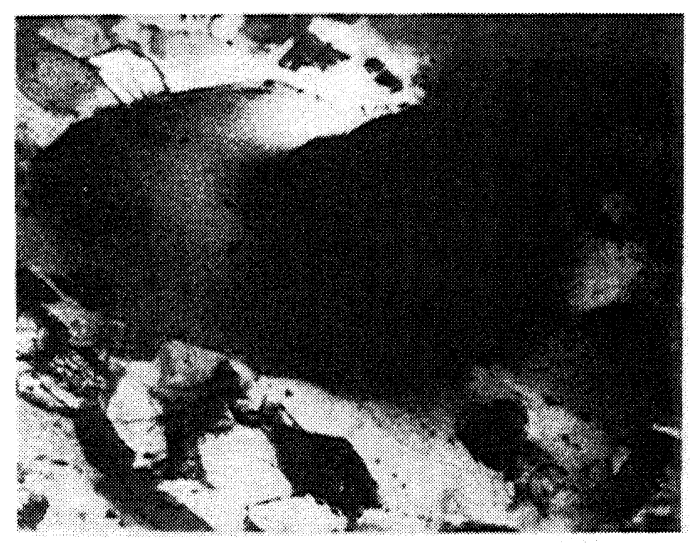

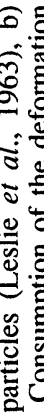

U

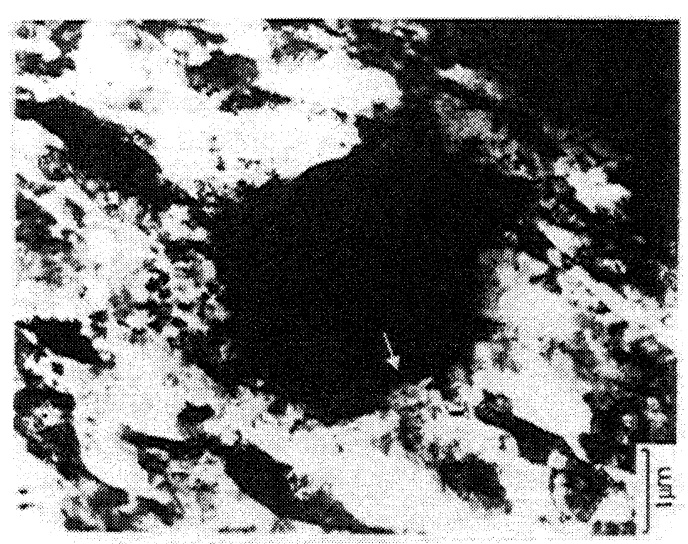

$\widehat{e}$

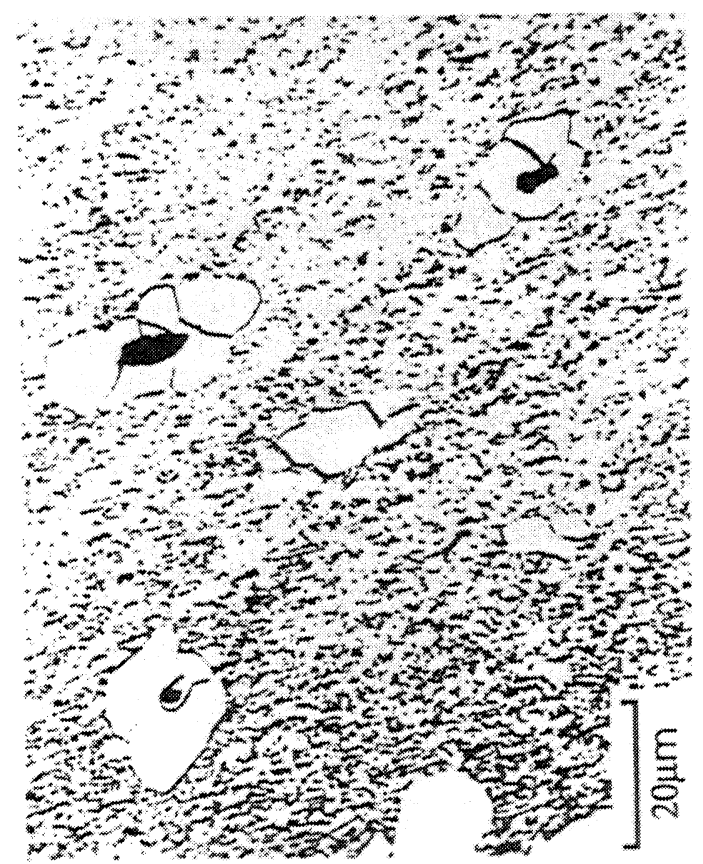

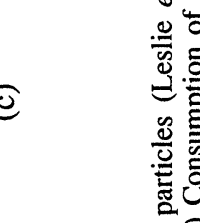

总

递立

ప్ర

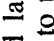

을

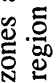

옹

$\underline{\underline{E}}$.

ํํํ.

串

해

迅

劳

总.

눙

읋

을

之ํㅗㅇ

ช్ర

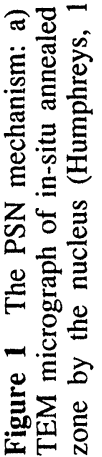




$$
\eta_{c}=\frac{4}{3} \frac{\gamma}{P_{D}^{M}}
$$

where $\eta_{c}$ is the critical particle size for PSN to occur. It should be pointed out that the pre-factor is only an uncertain approximation. The important point is that the critical particle size is inversely proportional to the driving pressure in the matrix.

Increasing the temperature of deformation brings a new dimension into the PSN picture. At higher deformation temperatures the situation may arise where dislocations annihilate at the same rate as they arrive at the particles and no deformation zones will be formed. This situation has been treated by Humphreys and Kalu (1987). Their analysis of a particle-containing Al-Si alloy which was deformed at a strain rate $\dot{\varepsilon}$ and temperature $\mathrm{T}$, showed that deformation zones only formed around particles of sizes $\eta>\eta^{*}$, where $\eta^{*}$ is given by:

$$
\eta^{*}=K(T Z)^{-\frac{1}{3}}
$$

Here, $\mathrm{K}$ is a material constant, $\mathrm{Z}=\dot{\varepsilon} \exp (\mathrm{Q} / \mathrm{RT})$ is the Zener-Hollomon parameter and $\mathrm{Q}$ is the activation energy. This formation-of-deformation-zone criterion needs to be balanced against the growth criterion given by Eq. (2). In Figure $2 a$ both criteria are plotted as a function of the Zener-Hollomon parameter. As indicated in this diagram, the growth criterion controls the PSN activity during commercial processing of aluminium alloys.

Increasing the strain increases the driving pressure in the matrix, i.e. the critical particle size is lowered (Eq. 2). An example of this is given in Figure $2 \mathrm{~b}$ which shows the conditions of particle size and strain for PSN at Si-particles in cold rolled aluminium. For the special case of hot deformation the driving pressure will be determined by the Zener-Hollomon parameter $(Z)$. The driving pressure will increase with increasing Z-value, i.e. PSN will be most efficient at high Zener-Hollomon parameters. This is schematically demonstrated in Figure $2 c$, where Eq. (2) has been used with a driving pressure $\mathrm{P}_{\mathrm{D}}^{\mathrm{M}}=\alpha \gamma_{\mathrm{SB}} / \delta$ where $\alpha$ is a geometric constant, $\gamma_{\mathrm{SB}}$ is the sub-boundary energy and $\delta$ is the subgrain size which according to Castro-Fernandez et al. (1990) is well described by $1 / \delta=A \ln (Z)-B$. An integration of the particle size distribution from the critical particle size in Eq. (2) has been undertaken (see also Eqs. 5-8).

\subsection{The orientations of PSN grains}

Single crystals: Experiments by Humphreys $(1977,1980)$ on single crystals of Al-Si alloys deformed in tension have established that the orientations of the PSN nuclei are contained within the spread of the deformation zone. Annealing of lightly rolled crystals of the same alloys resulted in a sharp recrystallisation texture which was rotated from the deformation texture by $30-40^{\circ}$ about a $<112>$ axis. Assuming single slip, Ashby (1970) predicted that the orientations of the subgrains inside the deformation zones should, for fcc metals, rotate around a $<112>$ axis lying in the slip plane and perpendicular to the slip direction. Such $<112>$ rotations were observed in $\mathrm{Al}-\mathrm{Cu}$ alloys by Russel and Ashby (1970) and in Al-Cu-Si single crystals by Humphreys (1979), both deformed in single slip. Engler et al. (1987) made similar observations in rolled, Bs-oriented $\mathrm{Al}-\mathrm{Cu}$ single crystals where two slip systems were active, both giving rise to $\langle 112>$ rotations. However, in differently oriented crystals, they found no $<112\rangle$ rotations. In experiments where the initial orientation of single crystals has been measured, a correlation between the orientation of the PSN nuclei and the initial matrix 


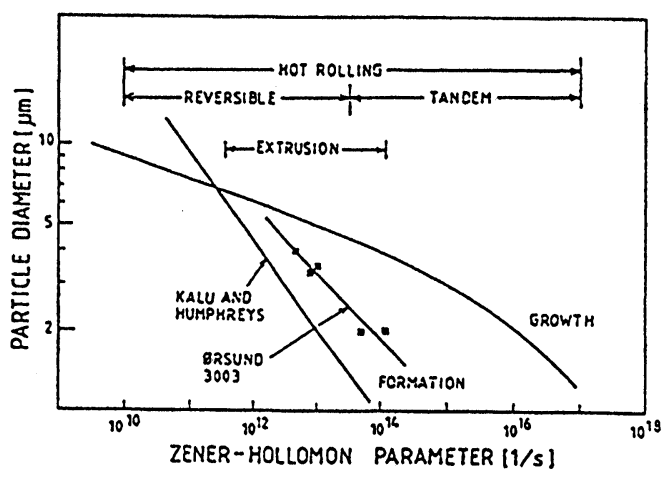

(a)

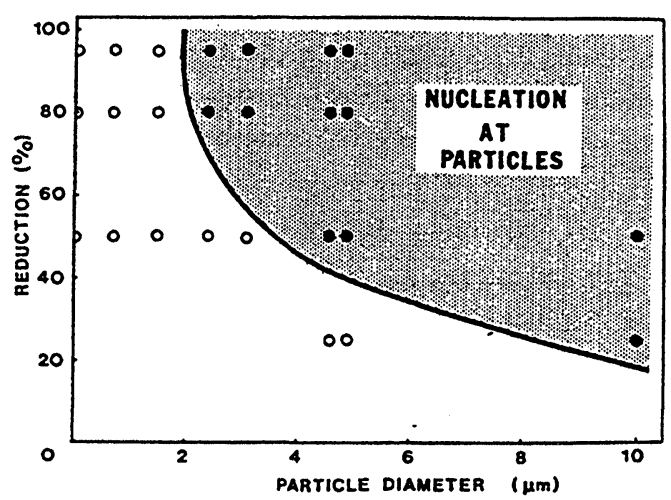

(b)

\section{PSN site density}

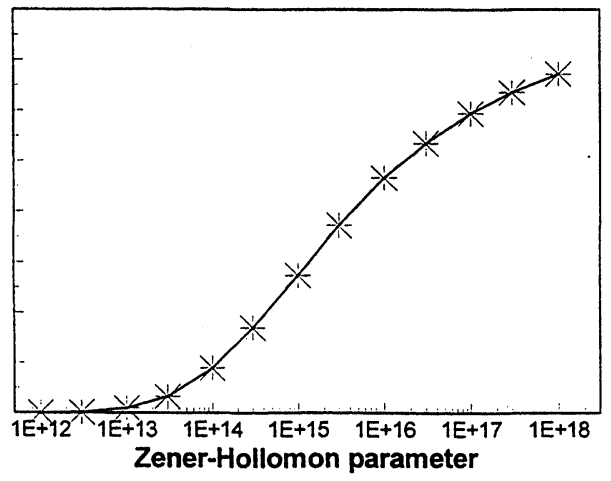

(c)

Figure 2 a) Conditions for the formation of deformation zones and growth of PSN-nuclei out of the zones as a function of Zener-Hollomon parameter. Typical hot deformation processes are indicated (Furu et al., 1993), b) The conditions for particle size and strain for PSN to occur at Si-particles in cold rolled aluminium (Humphreys, 1977) and c) Schematic variation in the density of PSN nuclei as a function of Zener-Hollomon parameter. 
orientation has been reported, e.g. Jack et al. (1989) and Humphreys and Ardakani (1994).

Polycrystals: In polycrystals the effects are more complicated. On account of the wide scatterings of initial orientations and the stress state, a more or less random orientation distribution of the subgrains in the deformation zones results (e.g. Herbst and Huber, 1978, Wassermann et al., 1978, Chan and Humphreys, 1984), and the PSN nuclei are either weakly textured or are approximately randomly oriented. Both the initial orientations around the particles and the size and shape of the particles will influence on the orientations within the deformation zones. The range of the orientations for potential nuclei is therefore great. This will give rise to nuclei spread over a wide range of orientations.

It appears to be a reasonable assumption that the PSN grains are nucleated in regions close to the particles as the orientation gradients and hence the recovery rates are highest in these regions. This picture is to some extent verified by the observations of a random texture of the PSN grains. Ørsund and Nes (1988) presented a model with a somewhat modified picture. Their model was used for interpreting experimental observations on an Al-Mn alloy where recrystallisation at high temperatures gave a rather random texture, while annealing at low temperatures gave a retained rolling texture. Their interpretation was that the PSN grains were nucleated close to the particles at high temperatures and in the peripheries of the deformation zones at low annealing temperatures. In the latter case the nuclei would actually grow into the deformation zone, driven by the high stored energy within it. Ørsund and Nes found little microstructural evidence of PSN originating in the peripheries of deformation zones, but their model has obtained support in a recent work by Rabet et al. (1995).

Some indications of preferred nuclei orientations appearing in the deformation zones of heavily strained materials have been reported in recent works by Engler and co-workers (1995, 1995a-b). At low levels of deformation ( $50 \%$ reduction) they reported a randomisation of the subgrain orientations within the deformation zones (see Figure 3a). At higher strains, however, a slight preferred occurrence of $P$ and NDrotated cube subgrains appeared in the regions close to the large particles (Figure $3 b$ ). Nuclei generated at the particles (investigated after a short time of annealing) also showed this weak preference of $P$ and ND-rotated cube (see Figure 3c). Weak recrystallisation textures with some preference of $\mathrm{P}$ and ND-rotated cube have been reported in various aluminium alloys where PSN is an assumably important nucleation mechanism, see e.g. Juul Jensen (1991), Lücke and Engler (1992), Engler et al. (1995a-b) and Vatne et al. (1995d).

A consequence of the general consensus and success of the PSN mechanism, is that many workers regard PSN as the only possible nucleation mechanism for randomly oriented recrystallised grains. However, a recent analysis by Weiland (1995) where a 3D sectioning technique was utilised, showed that less than $50 \%$ of all recrystallised grains could be associated with particles, while the recrystallisation texture contained about $75 \%$ randomly oriented grains, i.e. a significant fraction of random grains was not nucleated at particles. Additionally, not all grains that originated from particles were of random orientations, hence, more than $40 \%$ of the random grains were not nucleated by PSN. His analysis was for a cold rolled $\mathrm{Al}-\mathrm{Mn}(\mathrm{Fe}, \mathrm{Si})$ alloy where PSN is assumed to be particularly potent due to the ready formation of deformation zones during cold deformation. In the case of hot deformation, on the other hand, the deformation zones are partly demolished by dynamic recovery. This retards the efficiency of PSN 


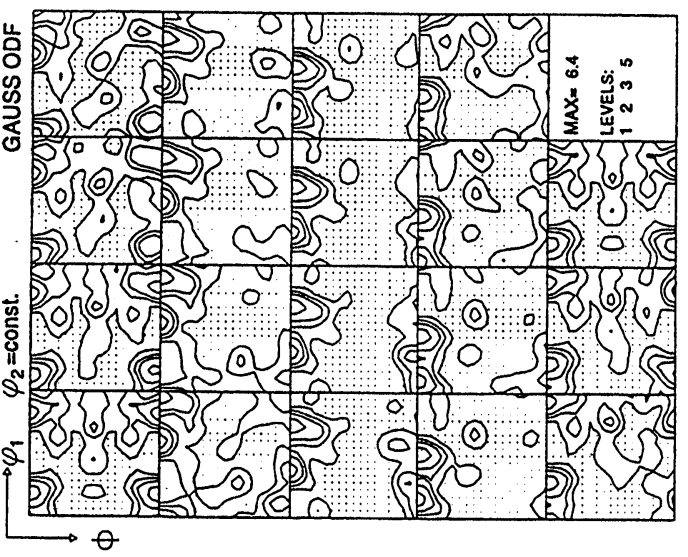

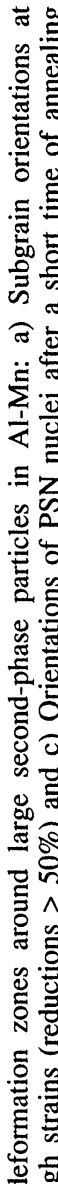

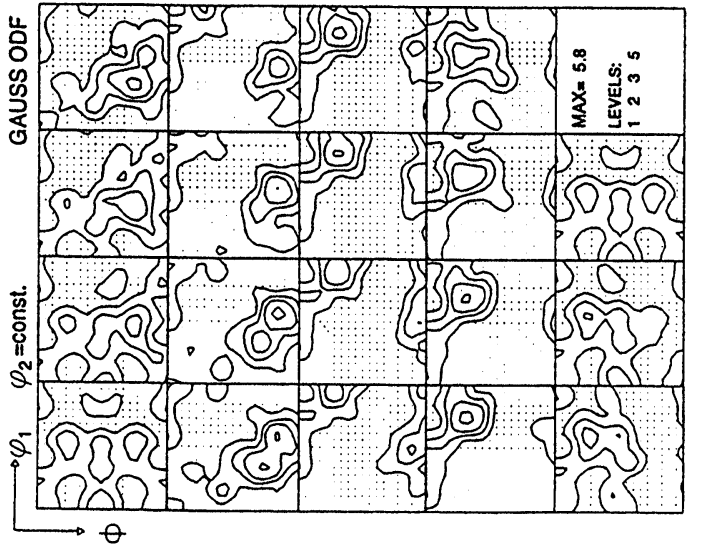

(3)

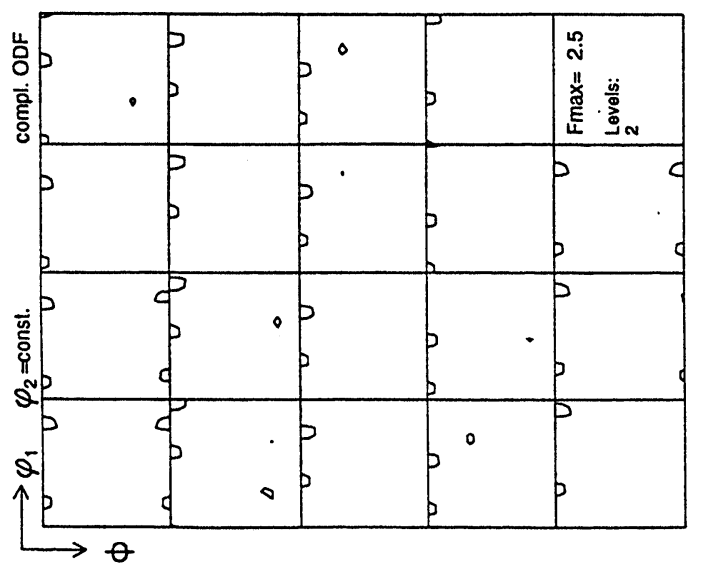


(Humphreys and Kalu, 1987). This means that PSN will hardly take place after deformation at high temperatures. Still, the recrystallisation textures of hot deformed aluminium alloys contain a considerable fraction of randomly oriented recrystallised grains, see e.g. Hutchinson et al. (1989) and Vatne and co-workers (1995, 1995a-b). This indicates that other nucleation mechanisms for randomly oriented grains exist in addition to PSN. It has been suggested by Vatne and co-workers $(1995,1995 \mathrm{c})$ that the nucleation of randomly oriented grains might take place in the boundary regions between stable deformation texture components. In order to provide compatibility between grains of different orientations during deformation, more (and other) slip systems will be active in the periphery of a grain (cf. relaxed constraints). This leads to deformation zones with large lattice rotations and strain accumulation that bridge two stable texture components of different orientations. In cases where the lattice rotations are large, the transition regions will obtain a more or less random orientation. Such random zones are expected to be potent nucleation sites since the subgrains in the zones will either be surrounded by high angle boundaries or they can easily obtain a high angle boundary character of a high mobility. The evolution of randomly oriented transition zones would be expected to occur more frequently in coarse-grained materials where it is more difficult to fulfill compatibility between the neighbour grains during deformation. Some support of such a mechanism has been provided in a recent work by Engler (1995) who investigated the orientations of nuclei from grain boundary regions in commercial purity aluminium. He found a weak texture with some preference of retained rolling components, but with large scatterings and a considerable randomization. Hutchinson (1989), Skjaervold and Ryum (1996) provided evidence for new recrystallised grains from grain boundaries which did not share either of the parent grains' orientations, i.e. in contradiction to the SIBM mechanism. It should be pointed out that these ideas are rather speculative and need further experimental verification, but the reasoning demonstrates a very important point: although PSN is well established as a nucleation mechanism, one should keep in mind that there may also be other nucleation mechanisms for randomly oriented recrystallised grains.

\subsection{A model for PSN from particles on grain boundaries}

In the analysis above, the location of the potential PSN particles in the microstructure was not considered. A reasonable assumption, however, is that particles situated on grain boundaries are more likely to nucleate recrystallised grains than others. Experimental indications of this have been provided by e.g. Bay and Hansen (1979) and Sircar and Humphreys (1994). There are two factors which may contribute to this. Firstly, the local strains near grain boundaries often differ from those in the grain interiors and secondly, the pre-existing high angle boundaries are likely to make the development of a nucleus easier and more rapid. These factors may become very important in cases where the PSN mechanism is not so efficient, e.g. in materials where the particle size is small or in hot deformed alloys where the deformation zones are poorly developed. In the following, a model where PSN is restricted to those particles that are in contact with high angle boundaries will be presented. It is pointed out that this is only a first-order-modelling-approach undertaken in order to illustrate the effects of grain boundaries in association with the PSN activity.

The first step becomes to calculate the fraction of particles in contact with grain boundaries. Let $f$ be the fraction of particles in the material and let $f_{P G B}$ be the fraction of particles in contact with grain boundaries. A material with an initial grain size $D_{0}$ 
will after a deformation to a strain $\varepsilon$ contain a surface density of boundaries, $A_{G B}$ (area of boundaries/unit volume):

$$
A_{G B}=\left(2 / D_{0}\right)\left(e^{\varepsilon}+e^{-\varepsilon}+1\right)
$$

In order to find the fraction of particles in contact with grain boundaries, the particle size distribution must be integrated. In aluminium, the large-particle-size distribution (frequency distribution) is well represented by a relationship of the following form (Strid et al., 1990):

$$
f(\eta)=H \exp (-L \eta)
$$

where $\mathrm{H}$ and $\mathrm{L}$ are parameters describing the particle size distribution. The total fraction of particles located on grain boundaries is found by the following calculation:

$$
f_{P G B}=\frac{\int_{0}^{\infty} 2 \eta A_{G B} f(\eta) d \eta}{\int_{0}^{\infty} f(\eta) d \eta}
$$

A combination of Eqs. (5) and (6) now gives the following fraction:

$$
f_{P G B}=\frac{4}{L D_{0}}\left(e^{\varepsilon}+e^{-\varepsilon}+1\right)
$$

The density (number/unit volume) of PSN sites is found by integrating the particle size distribution from the critical particle size, $\eta_{c}$, given by Eq. (2):

$$
N_{P S N}=f_{P G B} C \int_{\eta}^{\infty} f(\eta) d \eta
$$

where $\mathrm{C}$ is a constant that determines the number of nuclei generated from each overcritically large particle. The value of $\mathrm{C}$ will be of the order 1 and must be determined on an experimental basis. Using again the particle size distribution of Eq. (5), the PSN density becomes:

$$
N_{P S N}=f_{P G B} C N_{0} \exp \left(-\frac{4 L \gamma}{3 P_{D}}\right)
$$

where $f_{P G B}$ is given in Eq. (7) and $N_{0}=H / L$. On the assumption that PSN is the only nucleation site, the fully recrystallised grain size is given by:

$$
D_{r e x}=\left(\frac{1}{N_{P S N}}\right)^{1 / 3}
$$

From Eqs. (9-10) it becomes evident that a small initial grain size and a high strain should promote a small recrystallised grain size. Results by Vatne et al. (1995c) are suitable for validation of the model. They measured recrystallised grain sizes in an Al-Fe-Si alloy of 2 different initial grain sizes deformed to various strains. The constant $\mathrm{C}$ in Eq. (9) was determined by tuning the model to a recrystallised grain size of $22.5 \mu \mathrm{m}$ at $\varepsilon=2$ and $D_{0}=76 \mu \mathrm{m}$. The experimental and modelled results are compared in Figure 4. It is seen that the model gives a too strong response on a variation in initial grain size and a too weak response to a variation in strain. However, compared 
to a standard PSN model (corresponds to Eq. (8) with $\mathrm{f}_{\mathrm{PGB}}=1$, also included in Figure 4) the variation with strain is considerably improved. This is an indication that PSN is more efficient from particles located on grain boundaries. It must be emphasised, however, that there might be other nucleation sites which strength increases with increasing strain, e.g. nucleation from grain boundary regions.

\section{PARTICLE PINNING}

\subsection{The effect of small particles on nucleation and growth of recrystallised grains}

Particles will act as obstacles to the movement of grain boundaries. Since the nucleation of recrystallised grains involves the migration of (low angle) subgrain boundaries, this means that finely dispersed, small particles will retard both the nucleation and growth of recrystallised grains. The nucleation will be influenced in the sense that the GibbsThompson diameter for viable growth is increased through a lower effective driving pressure $\left(P_{D}-P_{Z}\right)$, where $P_{D}$ is the driving force and $P_{Z}$ is the pinning Zener drag from the small particles. This means that the number of nuclei will decrease. Also the growth rate, $G$, of the nuclei will be reduced according to $G=M\left(P_{D}-P_{Z}\right)$, where $M$ is the temperature-dependent mobility. The result of these two effects is slower recrystallisation kinetics and a larger recrystallised grain size. There are numerous examples of these effects in the literature, e.g. Nes (1976, 1979), Hansen and Bay (1981), Chan and Humphreys (1984), Furu et al. (1993), Doherty et al. (1989), Vatne et al. (1994b), Engler et al. (1995a), Benum et al. (1995) and Daaland and Nes (1995). In some cases the Zener drag might even be so large that recrystallisation is prevented, e.g. by $\mathrm{Zr}$ particles in aluminium (Bowen, 1990, Barlat et al., 1992). In HSLA (High Strength Low Alloyed) steels precipitates are used industrially as a valuable tool for preventing grain growth after recrystallisation (Silveira and Barbosa, 1993, Liu et al., 1995), i.e. for grain size control.

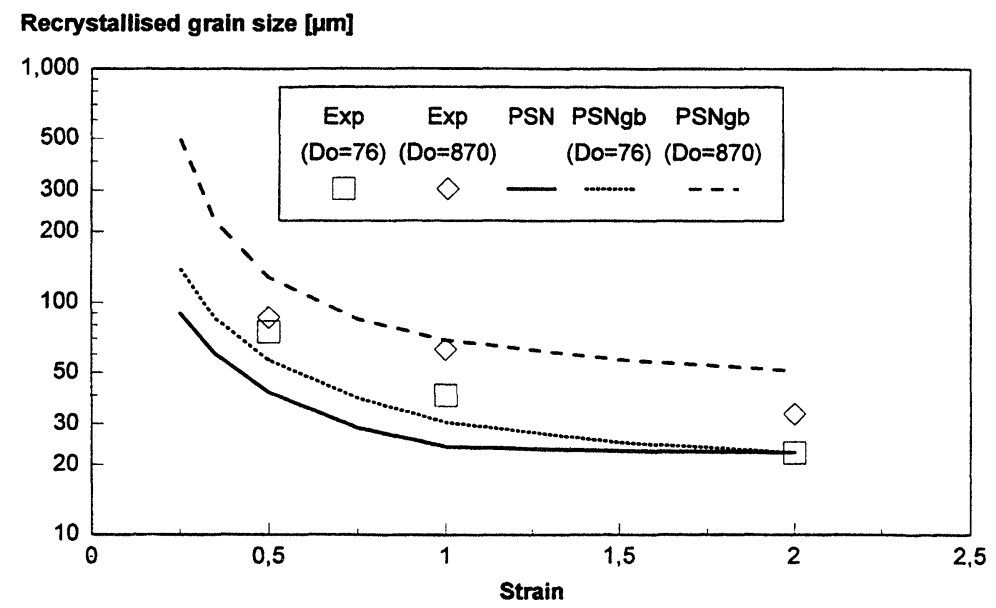

Figure 4 Comparison between experimental data and model results of recrystallised grain sizes in a cold rolled AlFe $\mathrm{Si}$ alloy of various strains $(\varepsilon)$ and initial grain sizes $\left(\mathrm{D}_{0}\right)$. Two models are included: ordinary PSN and $\mathrm{PSN}_{\mathrm{GB}}$ from particles on grain boundaries. Note that PSN is assumed to be the only nucleation mechanism in both cases. 
The first reported attempt to calculate the retarding force from particles was the early work by Smith (1948) in a discussion with Zener. The following expression was proposed:

$$
P_{z}=\frac{3}{2} \frac{f \gamma}{R}
$$

where $f$ is the volume fraction of particles, $\gamma$ is the boundary energy and $R$ is the radius of the particles. Improvements of this expression, e.g. by considering heterogeneous precipitation, usually leads to similar expressions, but with a different pre-factor. It is therefore common to write the Zener drag on the form $P_{z}=\alpha f \gamma / R$. From Eq. (11) it is seen that the most effective pinning force will result from a high fraction of small particles. With a sufficiently small spacing of thermally stable small particles, it is possible to prevent recrystallisation and preserve the deformed/recovered microstructure up to the melting temperature of the matrix. Quite a number of more or less ambiguous calculations have been made to improve this expression, for instance those by Hazzledine et al. (1980), Louat (1983), Nes et al. (1985, 1989), Hillert (1988) and Doherty et al. (1989). However, all these refinements give results close to the original Zener estimate. Nes et al. (1985) also showed that effects of particle shape and distribution are more important factors than the effect of the nature of the particle interface.

The expression above (Eq. 11) is a mean value for a given, constant fraction and size of particles. For processing of real materials, however, the situation becomes much more complex because the size and amount of particles change with changing processing conditions. Small particles may either be present in the material prior to annealing or they are precipitated concurrent with the recrystallisation process. In order to calculate the Zener drag from precipitates the following aspects have to be considered: (i) precipitation kinetics, (ii) amount of precipitates and (iii) size and distribution of the particles. For all 3 factors the phase boundary energy and the diffusivity of the precipitating elements are key parameters. Generally, 3 main cases are important in terms of recrystallisation:

(i) Dispersoids: Small particles may be present in the material prior to recrystallisation annealing. Such particles are usually referred to as dispersoids and are typically small particles generated during pre-processing. The dispersoids will be randomly distributed in the material, and stable dispersoids represent a static Zener drag which can be calculated using Eq. (11). Note that particle coarsening and dissolution may alter the Zener drag during annealing.

(ii) Precipitation on the subgrain structure during annealing: This is expected to be a very typical situation when annealing supersaturated alloys in which precipitates of intermediate phase boundary energies and diffusivities are precipitated. Precipitation on the substructure is favourable in terms of phase boundary energy, and the sub-boundaries also represent fast diffusion paths. This means that the critical stage is diffusion of elements into the subgrain boundaries. When the elements have reached the boundaries, diffusion is fast and a particle is easily nucleated. It should be pointed out that also homogeneous precipitation may take place during annealing. This is, however, a rather rare case which only occurs for particles of low phase boundary energies (coherent particles) and high diffusivities of the actual elements, e.g. in $\mathrm{Al}-\mathrm{Mg}-\mathrm{Si}$ and $\mathrm{Al}-\mathrm{Cu}$ alloys.

(iii) Precipitation on the recrystallisation front: This case is expected to take place for precipitates of high phase boundary energies and slowly diffusing elements. A low 
diffusivity means that the nucleation kinetics of the precipitates is slow compared with the progress of recrystallisation. The only effective mechanism for nucleation of the particles is that the moving grain boundary of a recrystallised grain collects solute atoms as it moves through supersaturated regions. The diffusion rate will be much higher along the boundary, which will stimulate the nucleation of pinning particles along it. This might have a dramatic effect on the growth rate of the recrystallisation front. Indications of this have been reported by Furu (1992), Vatne et al. (1995d) in an Al-Mn alloy, Daaland and Nes (1995) in an Al-Mn-Mg alloy (see Figure 11b) and Benum (1995) and Engler et al. (1996) in an Al-Fe-Si alloy.

\subsection{Effects of Zener pinning on microstructure}

The pinning of grain boundaries often leads to characteristic ragged boundary shapes. An example of such a ragged recrystallisation microstructure is given in Figure 5a. The reason for this characteristic boundary shape is that a boundary will be subjected to a very inhomogeneous pinning by the particles. The part of the boundary that is in contact with the particles will for a moment stop completely, while the unaffected parts will continue the growth and start bowing out between the particles. The result is a very inhomogeneous movement of the grain boundary which causes a ragged shape of the final recrystallisation structure.

Alloys containing small particles often show very elongated recrystallised grains, see Figure $5 \mathrm{~b}$. This is particularly the case for supersaturated alloys where particles are precipitated concurrent with the process of recrystallisation. A possible explanation for this lies in the distribution of the precipitated particles. Most of the particles will be precipitated heterogeneously on the deformation substructure (due to a lower nucleation requirement). A cold deformed material will develop a substructure of subgrains that are elongated in the direction of deformation, and the distribution of precipitates will become accordingly layered as schematically illustrated in Figure 5c. Nes et al. (1985) demonstrated that the Zener drag from such a particle distribution will be larger in the normal direction (ND in Figure 5c) than in the rolling direction (RD in Figure 5c). It should be pointed out that even in cases with no precipitation, tendencies of such effects can be observed. This is because of the elongated (sub-) grain structure which leads to a higher effective driving pressure (stored energy) along the rolling direction or even alignment of constituent particles which act in the same way as the precipitates. The point here is that this becomes much more pronounced when precipitation occurs.

A third typical microstructural feature related to precipitation is that of island grains, see Figure 5d. In this case, some grains will be so strongly inhibited by the precipitates that their growth practically stops compared to other grains. The reason might be local differences in the density and size of small particles. However, another more likely possibility in the cases of a concurrent precipitation reaction, is variations in nucleus size prior to the onset of precipitation, in the sense that the Zener drag will knock out the smallest nuclei while the largest are large enough for continued growth. The largest grains will consume the regions around the small inhibited ones, the result of which becomes small island grains within larger ones. The reason why the island grains are not consumed by the surrounding grains is the high density of precipitates on their boundaries. These make the boundaries immobile and prevent their consumption. Such structures have been reported by e.g. Chan and Humphreys (1984), Vatne et al. (1994b), Daaland and Nes (1995) and Benum et al. (1995). Island grains is also a common 


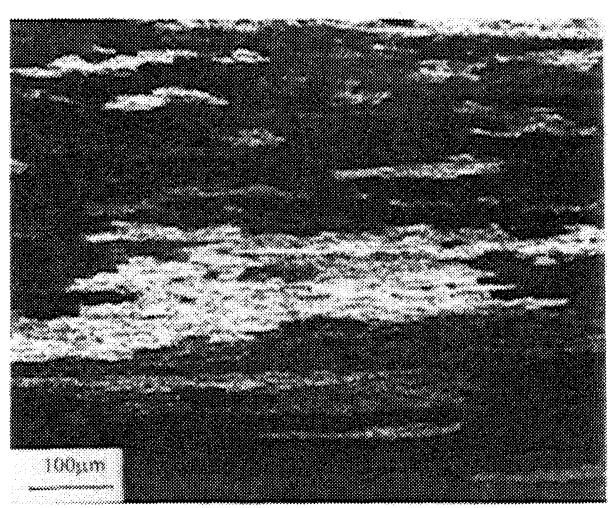

(a)

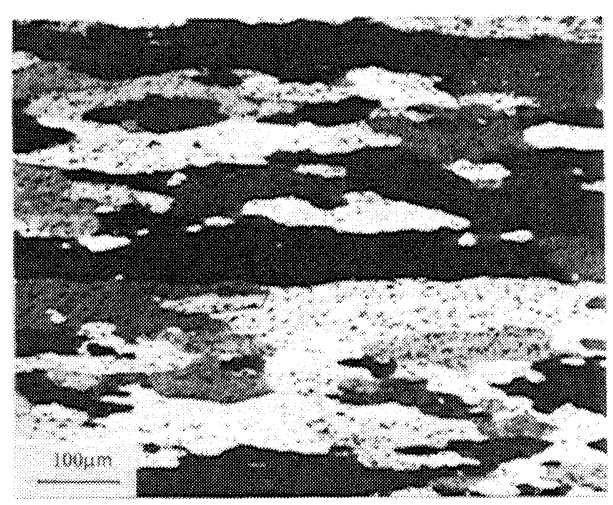

(b)

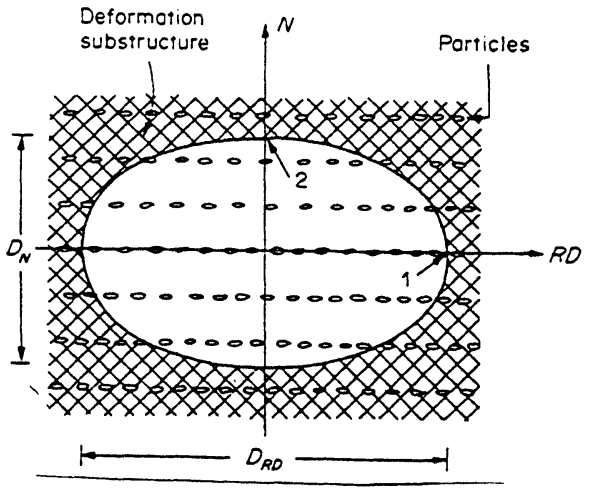

(c)

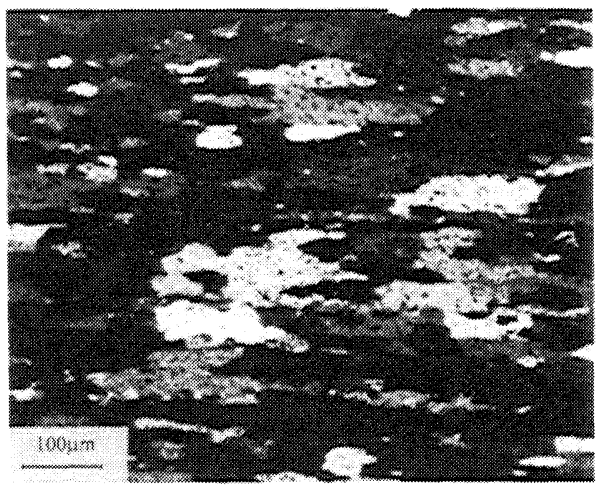

(d)

Figure 5 Typical examples of recrystallisation microstructures in an Al-Mn alloy in cases where small pinning particles interfere in the recrystallisation process: a) Ragged shape of recrystallised grains, b) Elongated grains in a supersaturated alloy where precipitating took place concurrent with the recrystallisation reaction, c) Schematic illustrating of a short transverse-longitudinal section of a recrystallised grain growing in a matrix of dispersoids precipitated on the deformation substructure and d) Recrystallisation structure consisting of island grains surrounded by larger grains. 
observation associated with secondary recrystallisation (anomalous grain growth), a phenomenon which is also closely associated with the presence of precipitates.

\subsection{Effects of Zener pinning on texture evolution}

The effect of small particles on recrystallisation texture evolution has not been particularly thoroughly treated in the literature. It is obvious, however, that due to their possible influence on nucleation and growth of recrystallised grains, small particles may significantly alter the texture evolution. This is especially so when the particles are precipitated on the substructure during the early stages of annealing. Under such circumstances both nucleation and growth will be inhibited. In the following, firstly a simple model will be presented for the purpose of demonstrating how certain recrystallisation texture components may be preferred in cases of precipitation. Secondly, some recent experimental observations will be presented in order to further demonstrate this phenomenon.

A qualitative model: In this model study two types of nucleation sites are considered: (i) Nucleation sites that for various reasons have a recovery advantage (or have a boundary energy advantage). This means that subgrains from these sites either have obtained a critical size (Eq. 1) prior to annealing or are able to reach it by recovery very early in the annealing sequence. Such a recovery advantage is well documented for the cube orientation, see e.g. Ridha and Hutchinson (1982), Samajdar and Doherty (1995), Bardal et al. (1995), Daaland and Nes (1995) and Vatne et al. (1994a-c, 1995ab). A similar advantage has also been suggested by Daaland and Nes $(1993,1995)$ for ND-rotated cube and the $P$ orientation (ii) Nucleation sites which require a considerable static recovery period in order to reach the critical size. This will be the situation for most nucleation sites as for instance PSN. The main point in terms of precipitation is that the nucleation sites in group (i) will reach an overcritical size prior to the onset of precipitation, while the other type of nucleation sites (ii) may be strongly inhibited because nucleation is slowed down by the precipitates.

The model is schematically outlined in Figure 6 which illustrates a case of a competition between PSN and nucleation from cube bands (and/or possibly bands of ND-rotated cube and $\mathrm{P}$ orientations). Figure $6 \mathrm{a}$ shows the situation prior to annealing $(\mathrm{t}=0)$. While an overcritically large subgrain is already present within the cube band the deformation zone around the particle only contains small subgrains which need static recovery annealing in order to reach a viable nucleus size. Figure $6 \mathrm{~b}$ shows the status after a certain annealing time $(t>0)$. The nucleus in the cube band has here bowed out and started consuming the surrounding matrix. In the deformation zone a nucleus is evolving. The figure also illustrates that now some precipitation has taken place, mainly on the deformation substructure. The precipitates increase the critical size for further growth. This has no effect on the large cube nucleus, but the smaller potential PSN nucleus is more severe. It is obvious that, depending on the amount of precipitation and the kinetics of precipitation and recovery, a large amount of the possible PSN nuclei will not become successful nuclei.

The schematic outline above can be more quantitatively formulated as follows; the critical diameter $\delta_{c}$ for a subgrain in a cube band to bow out and start growing into the surrounding matrix is given by: 
a)

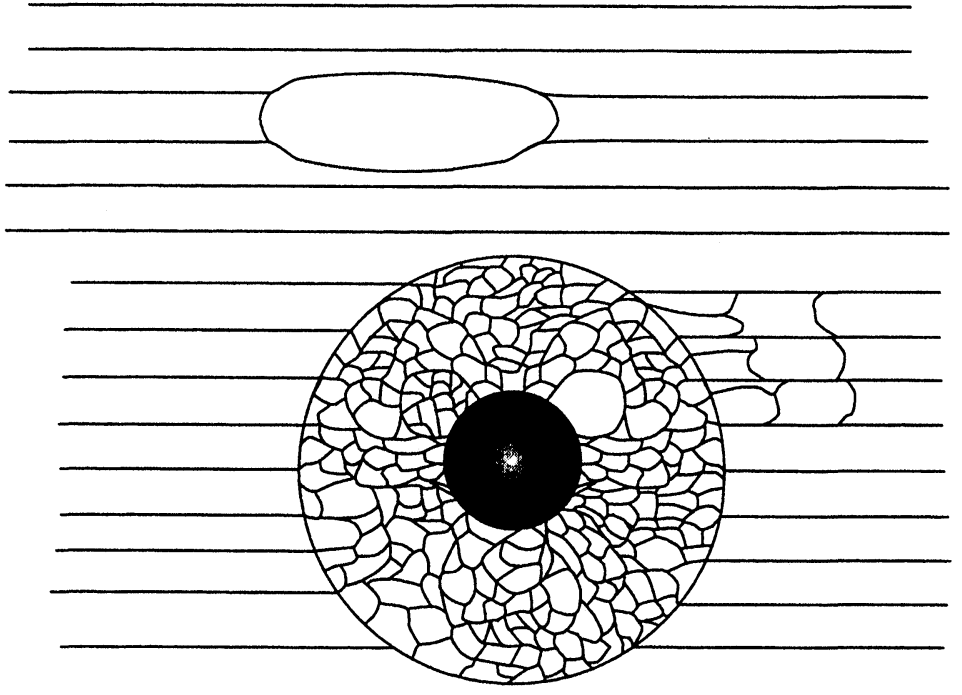

b)
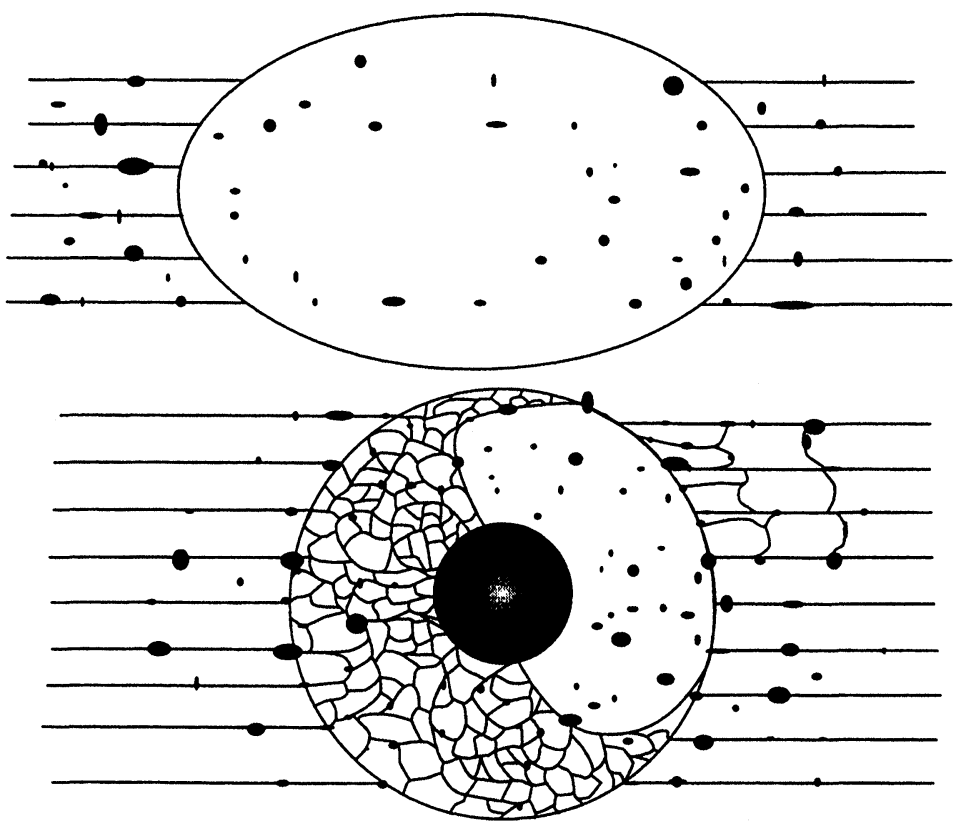

Figure 6 Schematic illustration showing how nuclei from banded nucleation sites (e.g. cube bands) with large subgrains are preferred on the expense of PSN grains in cases of precipitation: a) Prior to annealing (no precipitates), b) After a short annealing time (precipitation on substructure). 


$$
\delta_{C}=\frac{4 \gamma}{P_{D}^{M}-P_{Z}}=\frac{4 \gamma}{\left(\kappa / \delta_{M}\right) \gamma_{S B}-P_{Z}}
$$

where the driving pressure (stored energy in the subgrain boundaries) has been calculated as $\mathrm{P}_{\mathrm{D}}^{\mathrm{M}}=\left(\kappa / \delta_{\mathrm{M}}\right) \gamma_{\mathrm{SB}}, \kappa$ is a geometric constant, $\delta_{\mathrm{M}}$ is the matrix subgrain size and $\gamma_{\mathrm{SB}}$ is the sub-boundary energy which can be estimated from the Read-Schockley relation. Prior to the onset of precipitation $\left(\mathrm{P}_{\mathrm{Z}}=0\right)$ this gives:

$$
\delta_{c}=\frac{4 \theta_{c}}{\kappa \theta \ln \left(e \theta_{c} / \theta\right)} \delta_{M}
$$

where $\theta$ is the sub-boundary misorientation and $\theta_{c}$ is the critical value for a subgrain to be characterised as a high angle boundary. For a heavily cold rolled aluminium alloy $(\varepsilon>1)$, typical values are $\kappa=3, \theta=3^{\circ}$ and $\theta_{C}=15^{\circ}$. Using these values gives $\delta_{C} \sim 2.5 \delta_{M}$, i.e. a cube subgrain will become a viable nucleus as long as it reaches a size of about twice that of the average subgrain size in the matrix. The main argument now becomes that due to the large initial cube subgrain size and the high recovery rate, the largest cube subgrains might easily reach this critical value during the initial recovery period before precipitation starts. Thus, the nucleation from cube bands will not be so strongly affected by the precipitation reaction.

For PSN to succeed, on the other hand, a new grain will first have to consume the deformation zone around the particle and be further capable of growth out of the zone into the surrounding matrix. Humphreys (1979) has shown that the critical stage of PSN is not the consumption of the zone, but the growth out of it. The consumption of the deformation zone will require some time. During this period precipitaiton will take place. Hence, the grain will be exposed to a Zener drag when it starts growing out of the deformation zone and the critical nucleation size will increase. There are two contributions to the Zener drag: (i) from dispersoids, i.e. particles precipitated prior to annealing (randomly distributed) and (ii) from small particles precipitated on the deformation substructure or on the recrystallisation front during recrystallisation. The Zener drag from the dispersoids is given by $\mathrm{P}_{\mathrm{Z}}$ (dispersoids) $=(3 / 2) \gamma \mathrm{f} / \mathrm{r}$ (Eq. 11), where $\mathrm{f}$ is the volume fraction and $\mathrm{r}$ is the radius of the dispersoids. Typical values for an $\mathrm{Al}-1 \% \mathrm{Mn}$ alloy are $\mathrm{f}=0.001$ and $\mathrm{r}=0.05 \mu \mathrm{m}$ (Stid, 1990) which gives a retarding pressure of the order $\mathrm{P}_{\mathrm{Z}}$ (dispersoids) $10^{4} \gamma$. For the small particles precipitated concurrent with the recrystallisation reaction, one has to estimate the fraction of particles that are in contact with the moving grain boundary. Assuming now a flexible boundary adjusting itself to the precipitates on the substructure, this leads to a Zener drag of the form $P_{Z}=\pi n \gamma r$, where $r$ is the radius of the precipitates and $n$ is their area density. Typical values are $r=10^{-8} \mathrm{~m}$ and $\mathrm{n}=10^{14} \mathrm{~m}^{-2}$ which leads to a Zener drag of the order $\mathrm{P}_{\mathrm{Z}}$ (precipitates) $3 \cdot 10^{6} \gamma$. This value is considerably higher than that caused by the dispersoids, thus the total retarding pressure from precipitates is of the order $P_{Z} \sim 10^{6} \gamma_{G B}$. The driving pressure outside the deformation zone is the same as that for growth of cube grains and was in Eq. (12) estimated to be of the order $P_{D} \sim 10^{6} \gamma_{G B}$. This is of the same order as $\mathrm{P}_{\mathrm{Z}}$. This means that the PSN grains will have great difficulties growing out of the deformation zones because of the Zener drag from the precipitates.

Preference of the cube orientation during precipitation: In the following several experimental observations will be presented in order to illustrate the model outlined above. The first example is an Al-Mn alloy that was heat treated in such a way as to produce two different material conditions; one with large particles (referred to as 
3003A) and the other in a supersaturated condition (3003B). Both materials were cold rolled and annealed and recrystallisation textures and grain sizes were measured. Results for the annealing at $300^{\circ} \mathrm{C}$ are shown in Figure 7 (for details, see Vatne et al., 1995d). The recrystallisation textures essentially consisted of cube and random orientations with cube bands and PSN as likely nucleation sites. For the 3003A condition the grain size and the recrystallised cube fraction decreased with increasing rolling strain. The grain size decreases due to a higher driving pressure, while the amount of cube decreases due to a lower number of cube bands at high strains. For 3003B, on the other hand, both the grain size and the recrystallised cube fraction were higher and made a remarkable maximum at intermediate strains (with very elongated recrystallised grains, see Figure $5 \mathrm{~b}$ ). Measurements of the electrical conductivity showed a considerable increase for the 3003B conditions. This means that a strong precipitation reaction took place. Since annealing at higher annealing temperatures, where no precipitation took place, did not show this high cube fraction, this appears to be a good evidence for the preference of cube oriented grains during precipitation. The reason, as explained in the simple model above, is the large subgrains in the cube bands which will be less influenced by precipitates than the smaller PSN subgrains.

A similar phenomenon, but even more pronounced, was observed during annealing of a cold rolled Al-Fe-Si alloy which was supersaturated on $\mathrm{Si}$ and $\mathrm{Fe}$ (Benum, 1995). Specimens taken from rolled sheets $(\varepsilon=2)$ were isothermally annealed at temperatures in the range from $250^{\circ} \mathrm{C}$ to $425^{\circ} \mathrm{C}$. The grain size and texture were examined and the changes in electrical conductivity, $\Delta \sigma$, were measured with the results given in Figure 8a. Note that the grain size (Figure 8c) and the strength of the cube texture (Figure $8 \mathrm{~b}$ ) both decreased with increasing annealing temperature, and so did also the amount of precipitation occurring during the softening reaction (Figure 8a). At low annealing temperatures the transformation was totally dominated by cube grains which were considerably larger than grains of other orientations (Figure 8c). As the temperature increased a shift occurred from cube nucleation sites towards sites with an orientation
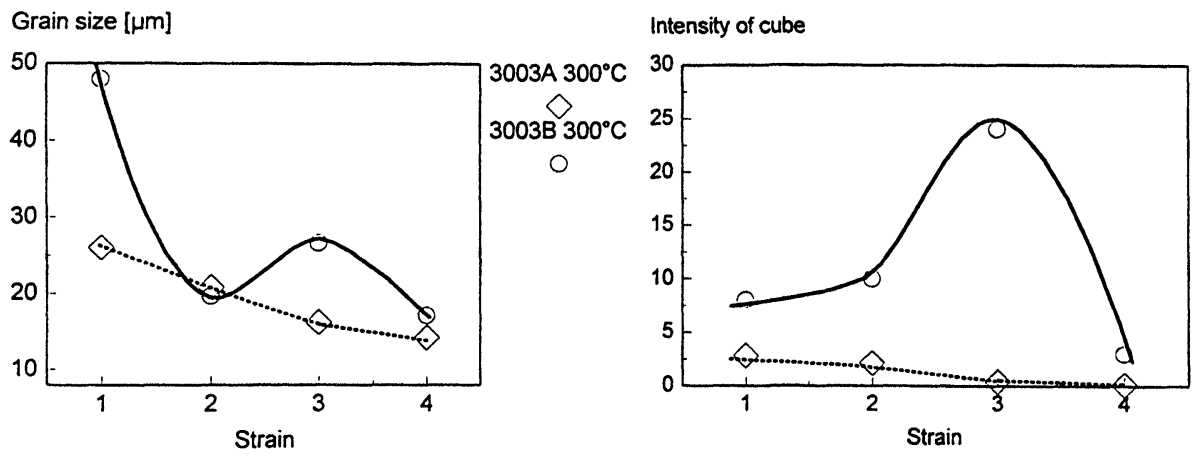

Figure 7 Data on a recrystallised Al-Mn alloy (AA3003) annealed at a temperature of $300^{\circ} \mathrm{C}$ where precipitation was stronger in the 3003B condition than in the 3003 A condition: a) Grain size and b) Cube fraction. 
spread belonging to the $\beta$-fibre. A typical aspect of the low temperature transformation was that the grains of $\beta$-fibre orientations grew very slowly to stagnate all together, while the cube grains grew faster and totally dominated the transformation. This resulted in large cube grains surrounding colonies of smaller grains, or small grains were left as island grains inside the large cube grains. An important conclusion becomes that this transformation changeover with increasing temperature from one type of site (cube) to another family of sites ( $\beta$-fibre) is a precipitation-induced effect. This conclusion is based on the following two observations: (i) The only significant microstructural change accompanying the temperature-induced texture/grain size transition is the associated precipitation effect and (ii) the existence of small island grains inside large grains implies the presence of small particles stabilising the island grains, or else they would have collapsed (see Section 3.2). It follows that the transition in texture and microstructure probably reflects a selective Zener pinning effect where the nucleation and growth of one type of sites are less affected by precipitation than the other type. The reason is as already stated above that the cube oriented subgrains are larger than other subgrains in the cold rolled sheets. This was verified by subgrain size measurements in SEM (EBSP mode). The analysis showed that the average subgrain size of cube oriented subgrains was $40 \%$ larger than the average subgrain size (after a short recovery annealing). Therefore, most of the cube oriented subgrains will probably be overcritically large already in the as-rolled condition and serve as nucleation sites, while other sites need an initial recovery period to achieve the viable size. If a precipitation reaction is overlaid the recrystallisation reaction, these slower evolving sites become victims to precipitation and the result is slower growth or total stagnation of these grains. The number of cube nuclei and nuclei of other orientations is schematically outlined in Figure 9 for three levels of precipitation. A large amount
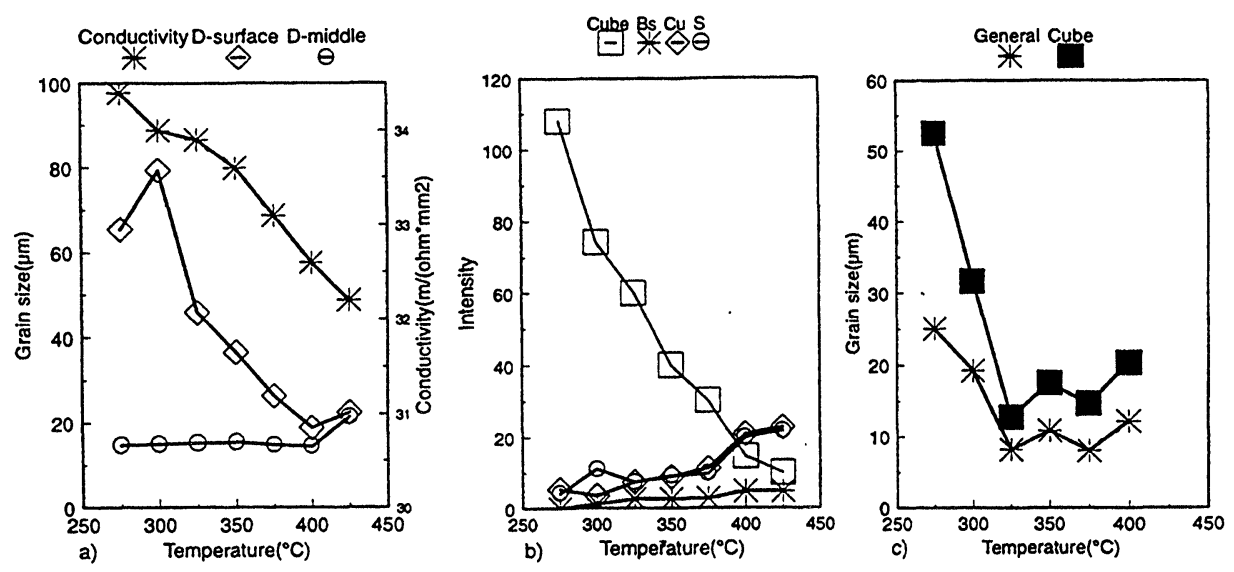

Figure 8 Cold rolled $(\varepsilon=1.9)$ and isothermally annealed Al-Fe-Si: a) Average recrystallised grain size and electrical conductivity, b) Intensity of the recrystallisation texture components and c) Average grain size of cube grains compared to grains of other orientations (measured by the EBSP-technique), all as a function of annealing temperature. 
of precipitates yields few nuclei, preferentially cube oriented subgrains, Figure 9a. No precipitation yields a large number of nuclei, i.e. a recrystallisation structure with a weak cube texture and small grains, Figure 9c.

Precipitation-induced preference of ND-rotated cube and the $P$ orientation: An Al-1wt\% Mn- $0.5 \mathrm{wt} \% \mathrm{Mg}$ alloy was initially hot rolled (no recrystallisation occurred during hot rolling) followed by cold rolling (total strain of $\varepsilon=6.5$ ) and annealing at temperatures of $300^{\circ} \mathrm{C}$ and $450^{\circ} \mathrm{C}$ (Daaland and Nes, 1995). Annealing at $300^{\circ} \mathrm{C}$ resulted in a very inhomogeneous grain structure containing a wide spread of grain sizes, ranging from $10 \mu \mathrm{m}$ to $70 \mu \mathrm{m}$. As can be seen from the ODF given in Figure 10b, the grain structure after annealing is associated with a characteristic texture consisting of a major ND-rotated cube component, $\{001\}<310\rangle$, and a minor $\mathrm{P}$ component, $\{110\}<111\rangle$. Annealing of the material at $450^{\circ} \mathrm{C}$ resulted in a totally different grain structure with equiaxed grains of average size $12 \mu \mathrm{m}$. In addition, a much weaker texture was found, but with the same individual texture components, Figure 10c.

The EBSP-technique was applied for more detailed investigations of the recrystallisation mechanism during annealing at $300^{\circ} \mathrm{C}$. From a series of partly recrystallised samples the size evolution of grains of different orientations (ND-rotated cube, $\mathrm{P}$ and cube) was followed, see Figure 11a. The ND-rotated cube and $\mathrm{P}$ grains are seen to grow significantly faster than the grains of random orientations, though only in the initial stage of annealing $(<800 \mathrm{sec})$. It is noted that, according to the oriented growth theory, both these recrystallisation texture components are associated with a fast growing $40^{\circ}<111>$ orientation relationship with respect to the $\mathrm{Cu}$ component. The grains belonging to the random category, however, seem to stop growing completely after reaching a size of approximately $7-8 \mu \mathrm{m}$ in average diameter. The small and equiaxed grains with a random orientation were clearly associated with the large particles in the structure, and it is reasonable to assume that they have been formed by particle stimulated nucleation (PSN). The growth of these PSN-grains was obviously hindered and they were often engulfed by larger recrystallised grains, becoming "island" grains. On further annealing the largest grain for all components seems, in fact, to grow at the same rate. In a classical oriented growth situation the $40^{\circ}<111>$ component should have continued to grow at a higher rate than the random component during the entire transformation, as long as the preferred $\mathrm{Cu}$ orientation still remained as part of the deformation texture. However, this was not observed, i.e. a classical oriented growth interpretation can be excluded.

Measurement of electrical conductivity (Figure 11b) demonstrated that annealing at the low temperature resulted in precipitation of $(\mathrm{Fe}, \mathrm{Mn})$-bearing phases occurring concurrent with the recrystallisation reaction. Hardness measurements have also been included in the figure to indicate the kinetics of the recrystallisation reaction. During annealing at $450^{\circ} \mathrm{C}$ no increase in conductivity was observed during the recrystallisation period, demonstrating that at high temperature the recrystallisation reaction was able to precede without interference from precipitating second phases. The obvious question now is: why does the precipitation reaction, during low temperature annealing, only affect the randomly oriented grains (i.e. the PSN activity) and not the growth of the other components? Detailed investigations of the nucleation sites for P and ND-rotated cube were not undertaken in this material, but based on the characterisation of cube nucleation sites as banded features in a hot rolled Al-Mg-Mn alloy (Daaland and Nes, 1995, Vatne et al., 1995b) a reasonable hypothesis in the present case may be stated as follows: (i) The texture evolution during recrystallisation can be described as a 

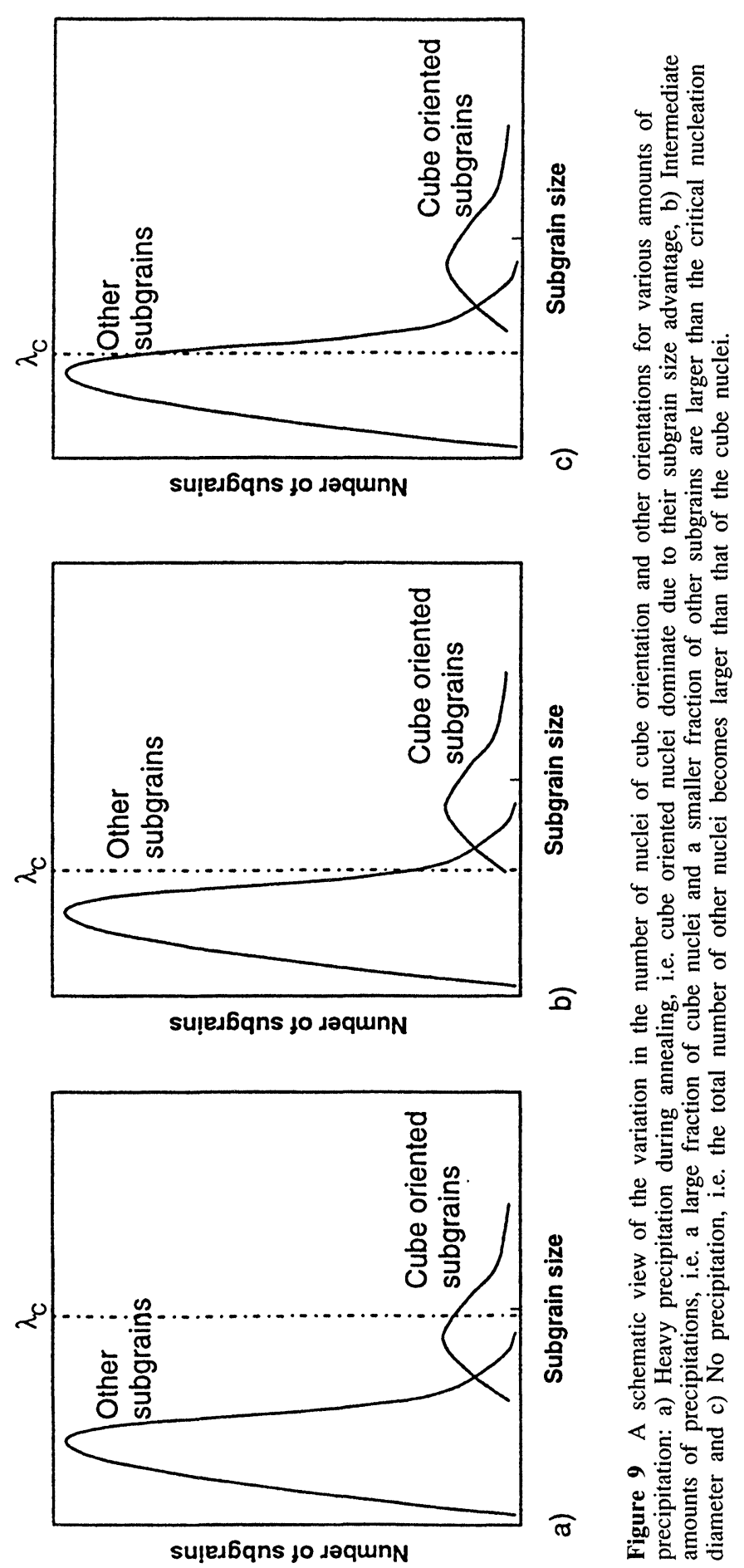

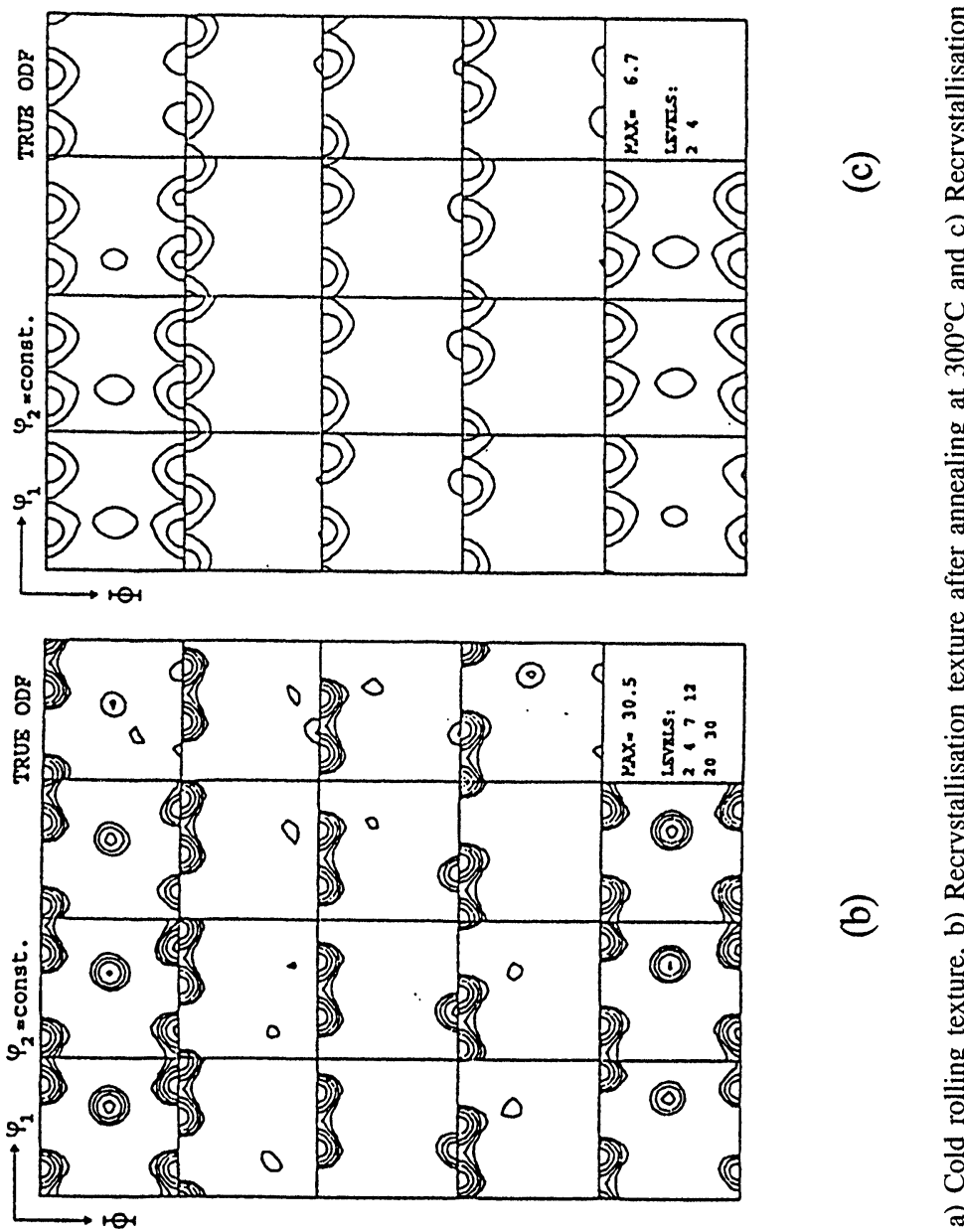

2

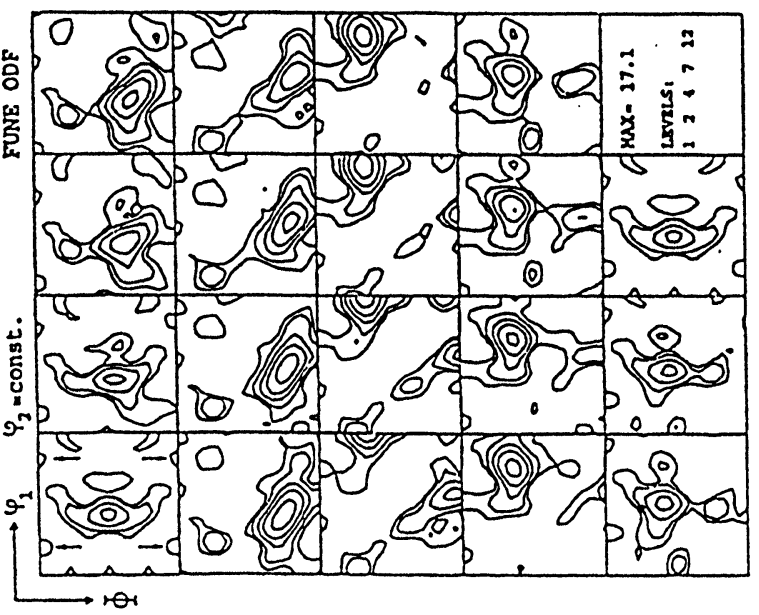



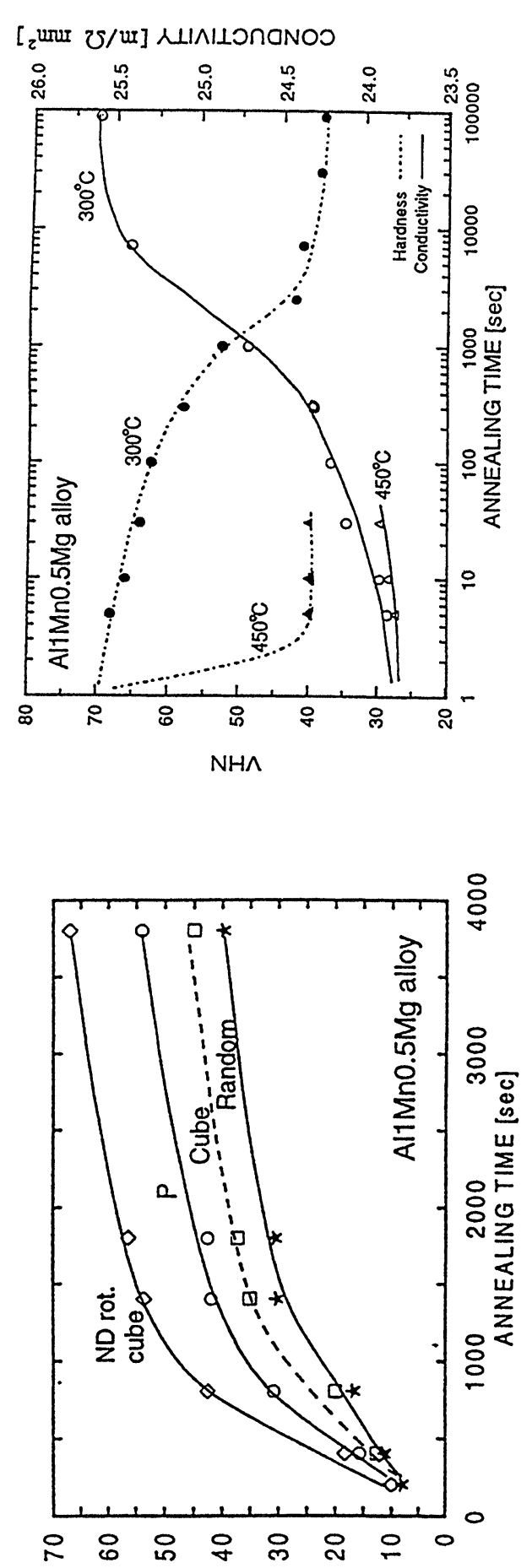

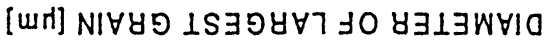


competition between PSN and nucleation from banded features within the deformation microstructure. (ii) Nuclei of sizes equal to (or larger than) the Gibbs-Thompson diameter are expected to be present inside these bands of ND-rotated cube, $\mathrm{P}$ and cube orientation, in the as-deformed condition. It is emphasised that peaks at the ND-rotated cube and $\mathrm{P}$ positions were found in the ODF of the as-deformed material, Figure 10a. This means that the same arguments of selective Zener pinning can be used to explain these results.

Modelling hot deformation - effects of precipitation: Quite recently Vatne and coworkers $(1995,1995 \mathrm{e}-\mathrm{f})$ have developed a model for predicting recrystallisation kinetics, textures and recrystallised grain sizes after hot deformation of aluminium. The model can be used for single pass as well as multipass hot deformation. The model relies on the calculation of the density of nuclei originating from three site categories: PSN, cube bands (which are retained cube grains from the starting material which survived the deformation) and grain boundary regions. Plane strain compression of commercial purity aluminium was undertaken in order to test the reliability of the model. Deformation and annealing was undertaken at two different temperatures of $300^{\circ}$ (all samples with Zener-Hollomon parameters $Z>3.10^{13} \mathrm{~s}^{-1}$ ) and $400^{\circ}$ (all samples with ZenerHollomon parameters $Z>3 \cdot 10^{13} \mathrm{~s}^{-1}$ ). The experimental results were at first rather surprising (Figure 12). Both the cube fraction and the recrystallised grain size showed a transition towards larger values as the temperature was lowered to $300^{\circ}$. It was shown by conductivity measurements that precipitation took place during annealing at the low temperature of $300^{\circ}$, but not at $400^{\circ}$. Therefore, a small Zener drag was included in the model for these samples. Experimental data and model predictions are plotted in Figure 12 and show a good agreement. It is seen that the cube fraction and the grain size decrease with increasing Zener-Hollomon parameter. This is due to a higher PSN efficiency and a lower cube stability at lower deformation temperatures. With increasing strain the grain size decreases due to a higher driving pressure (more nuclei generated), while the cube fraction increases due to a larger surface area of the cube bands (more cube nuclei). The shift in the curves are solely due to the precipitation reaction taking place at the low annealing temperature.

Alternative interpretations: In all cases above it was demonstrated that precipitation could explain the formation of sharp recrystallisation textures at low-temperature annealing, especially the cube orientation. The explanation appears reasonable and welldocumented, but may there exist other explanations for this phenomenon? Growth selection has often been used to explain the strong cube recrystallisation texture in aluminium. Growth selection has been ruled out in these cases because: (i) growth rate measurements showed no significant differences between cube grains and other grains at high-temperature annealing $\left(\mathrm{P}_{\mathrm{z}}=0\right)$, (ii) grains of cube orientation were of the same average recrystallised grain size or only slightly larger (due to the initial size advantage) than grains of other orientations at high-temperature annealing and (iii) a growth selection effect should be annealing temperature invariant. A phenomenon referred to as "orientation pinning" by Juul Jensen (1995) and also used by Doherty et al. (1995) and Vatne et al. (1995, 1995f) has recently been used for interpretation of recrystallisation textures. Orientation pinning occurs when a recrystallised grain of a given orientation grows into deformed material of its own orientation. This results in a low angle boundary and the growth of the recrystallised grain will practically stop due to the low mobility of low angle boundaries. Can orientation pinning explain the effects reported here? The observation of the growth behaviour in Figure 11a is 

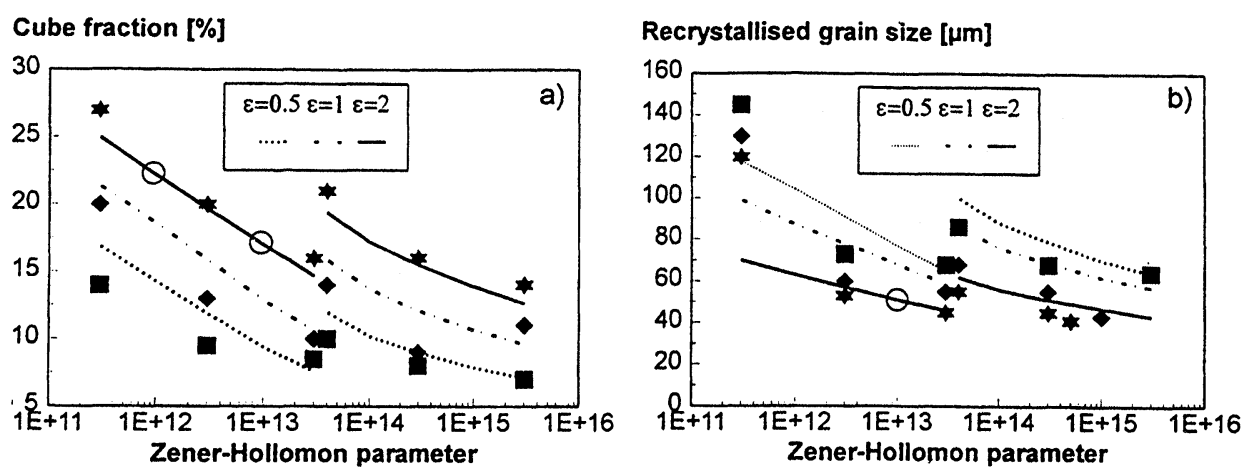

Figure 12 Comparison between experimental (plane strain compression) data and model predictions for commercial purity aluminium with initial grain size of $50 \mu \mathrm{m}$ and initial cube fraction of $12 \%$ : a) Recrystallised cube fraction and b) Recrystallised grain size, as a function of Zener-Hollomon parameter for various strains (lines: model, filled symbols: experimental data from Juul Jensen et al., 1994).

interesting with respect to orientation pinning. It is seen that the growth rates of the main recrystallisation components vary in the period $\sim 100-800 \mathrm{sec}$. This may be associated with an orientation pinning effect. Nucleation sites were not characterised in this material, but the global ODF of the as-deformed condition showed that only very small regions of $\mathrm{P}$, ND-rotated cube and cube were present in the as-deformed material. This means that the recrystallised grains of these orientations will be very little influenced by orientation pinning, while grains of other orientations may be more likely to grow into regions of their own orientation. A validation of such a hypothesis would be to measure the spacing between regions of similar orientation in the asdeformed condition. If this showed that $\mathrm{P}$ oriented regions has the largest spacings, orientation pinning could be used as an argument for its higher observed growth rate. The growth advantage is seen to rapidly fall off with increasing annealing time. This may be because impingement of recrystallised grains eventually becomes the most important growth-rate limiting factor. It should be pointed out that the orientation pinning effects in this case are small since all of the orientation groups P, ND-rotated cube, cube and random occupy only small volumes in the material. According to orientation pinning the fastest growing grains should be the random component, but after all this component is the slowest, i.e. orientation pinning is likely not so important in these cases. The cases where orientation pinning is expected to be important is for the growth of grains with the same orientation as a main component in the deformation texture, like retained rolling components. Vatne et al. (1995, 1995f) also reported a case where the growth of cube grains was most likely reduced due to orientation pinning, the reason being an extremely high as-deformed cube fraction of 35\%. Further, orientation pinning is in no way able to explain the temperature dependence of the cases given above. Orientation pinning should like growth selection be annealing temperature invariant. Hence, the conclusion becomes that only precipitation is able to explain the strong effects on recrystallisation textures presented here. 


\subsection{The importance of pinning particles in grain size control in commercial alloys}

It is important to realise that the Zener drag pressure will not only interfere in the growth of recrystallisation, but also in the nucleation of recrystallised grains through the Gibbs-Thompson restriction on the critical nucleus size. It follows that the critical size of a viable nucleus goes towards infinity as the Zener drag approaches the value of the driving pressure, and common sense tells us that the density of potential sites will decrease with decreasing net driving force. The critical particle dispersion that corresponds to the inhibition of recrystallisation will in the following be referred to as $[\mathrm{f} / \mathrm{r}]_{\text {crit }}$, while $[\mathrm{f} / \mathrm{r}]_{\mathrm{t}}$ refers to the dispersion level which defines the transition from a grain growth controlled to a recrystallisation controlled grain size.

How the density of available nucleation sites and the Zener drag determined the stable grain size which evolves as a result of the annealing of a deformed metal, has been treated by Nes and Hutchinson (1989). With reference to the schematic diagram in Figure 13a their main findings can be summarised as follows:

(i) $f / r<[f / r]_{1}$ : In this case the recrystallised grain size $\left(D_{\text {rex }}\right)$ is less than the grain size obtained by subsequent grain growth $\left(\mathrm{D}_{\mathrm{gg}}\right)$, i.e. there is a potential for considerable grain growth after recrystallisation. If a dispersion of particles (of a fraction $f$ and an average size $r$ ) is present in the material, it is well established that normal grain growth will stagnate (due to the retarding Zener drag) at an average grain size $D_{g g}=\alpha r / f$ (Rath and $\mathrm{Hu}, 1969)$. This situation applies to hot rolling of many plain and micro-alloyed steels where an abundance of nucleation sites for recrystallisation is supplied by the austenite grain boundaries. It also typifies copper and many of its alloys which contain only a small fraction of pinning second phase particles which is not large enough to prevent grain growth (see Figure 13b).

(ii) $[\mathrm{f} / \mathrm{r}]_{\mathrm{r}}<\mathrm{f} / \mathrm{r}<[\mathrm{f} / \mathrm{r}]_{\text {crit }}$ : In this regime the grain structure is recrystallisation controlled, i.e. further rapid grain growth subsequent to recrystallisation is prevented by pinning particles. This is generally the case during processing of aluminium alloys, but applies also to some steels, Figure $13 \mathrm{~b}$. Both $[\mathrm{f} / \mathrm{r}]_{\mathrm{t}}$ and $[\mathrm{f} / \mathrm{r}]_{\text {crit }}$ will be functions of the rolling reduction $(\varepsilon)$ or the driving pressure $\left(\mathrm{P}_{\mathrm{D}}\right)$ as outlined in Figure $13 \mathrm{a}$ as well as the density of heterogeneities which are potential sites for nucleation (Nes and Wert, 1984).
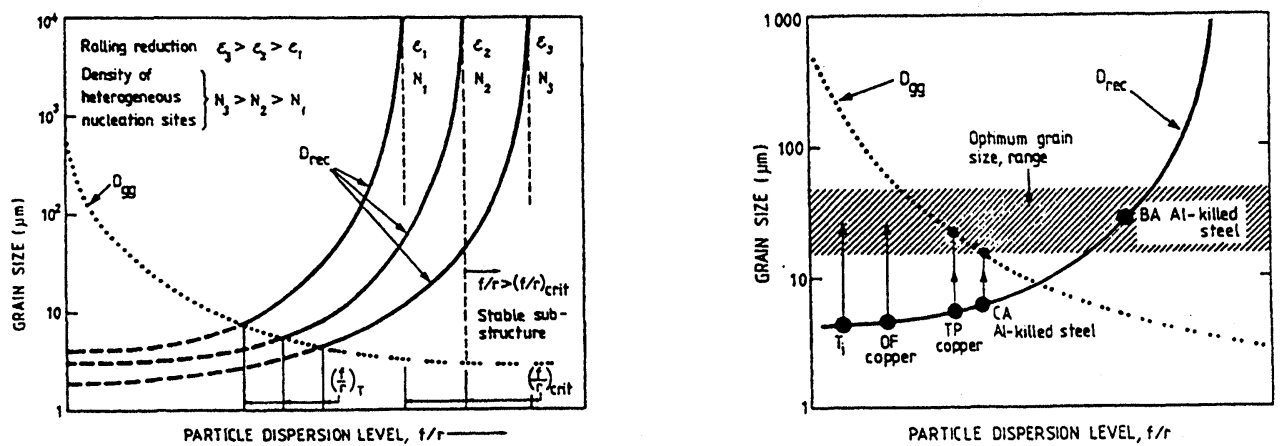

Figure 13 Grain size control in commercial alloys: a) Different ways in which the grain size after annealing of a cold worked metal depends on second phase dispersion level (Zener drag) and b) Schematic diagram showing mechanisms for grain size control for various commercial sheet products (Nes and Hutchinson, 1989). 
(iii) $\mathrm{f} / \mathrm{r}>[\mathrm{f} / \mathrm{r}]_{\text {crit }}$ : The Zener drag has now reached a level which prevents recrystallisation from occurring. In other words, the deformation structure has been stabilized by the dispersion of small particles. Especially in the extrusion of aluminium alloys, many applications require a non-recrystallised structure. Exceedingly high dispersion levels can in aluminium alloys be obtained by combining small additions of $\mathrm{Zr}$ and $\mathrm{Mn}$. The recrystallisation temperature can be increased to temperatures well above $500^{\circ} \mathrm{C}$ by such additions, which enables several interesting applications and properties. Plastic deformation of such alloys at around $\mathrm{T}_{\mathrm{m}} / 2$ may cause strain induced continuous recrystallisation, a phenomenon which has been used commercially in the development of a new generation of superplastic aluminium alloys (e.g. Stowell, 1983).

\section{CONCLUSION}

In this paper the effect of particles on the evolution of recrystallisation textures and microstructures has been covered. Particles influence the recrystallisation process in two fundamentally different ways: (i) through the formation of recrystallised grains in deformation zones around large, hard particles (PSN) and (ii) through pinning of grain boundary movement by small particles. The PSN mechanism is widely accepted as an important and often governing nucleation mechanism in aluminium alloys. Despite the large amount of work on PSN that has been undertaken the last 25 years, there are still unresolved questions related to the details of the deformation zone, the efficiency of the mechanism and the orientations of the PSN nuclei. The effect of small particles was for the first time considered as early as in 1948, but little work has been made with respect to their effect on texture evolution. The recent experimental results reviewed here have shown that large effects on the recrystallisation texture evolution may be caused by small precipitated particles.

\section{References}

Ashby, M. F., (1970). Philos Mag., 21, 399.

Bardal, A., Lindseth, I., Vatne, H. E. and Nes, E. (1995). 16th Ris $\phi$ Int. symposium, (eds. N. Hansen et al.), 261, Roskilde, Denmark.

Barlat, F., Breme, J. C. and Liu, J. (1992). Scripta met., 27, 1121.

Bay, B. and Hansen, N., Met. (1979). Trans., 10A, 279.

Benum, S. J., (1995). PhD Thesis, The Norwegian Institute of Technology, Trondheim, Norway.

Benum, S. J., Daaland, O., Espedal, A. B. and Nes, E. (1995). 16th Ris $\varnothing$ Int. symposium, (eds. N. Hansen et al.), 261, Roskilde, Denmark.

Bowen, A. W., (1990). Mat. Sc. Tech., 6, 1058.

Castro-Fernandez, F. R., Sellars, C. M. and Whitemann, J. A. (1990). Mat. Sc. Tech., 6, 453.

Chan, H. M. and Humphreys, F. J. (1984). Met. Sci., 18, 527.

Daaland, O. (1993). PhD Thesis, The Norwegian Institute of Technology, Trondheim, Norway.

Daaland, O. and Nes, E. (1995). Acta met., in press.

Doherty, R. D., Li, K., Kashyap, K., Rollett, A. R. and Srolovitz, D. J. (1989). Proc. 10th Ris $\phi$ Int. symposium, (eds. Bilde-Sørensen et al.,) 403, Roskilde, Denmark.

Engler, O., Hirsch, J. and Lücke, K. (1987). in "Textures of materials", Proc. ICOTOM 8, (eds. J.S. Kallend and G. Gottstein), 637, Warrendale, PA, Met. Soc. AIME.

Engler, O., Hirsch, J. and Lücke, K. (1995a). Acta met., 43, 121.

Engler, O., Yang, P. and Kong, X. W. (1995b). Submitted to Acta met.

Engler, O. (1995). To appear in Mat. Sc. Tech., special issue on "Textures on a microscale".

Engler, O., Vatne, H. E. and Nes, E. (1996). Mat. Sc. Eng., A205, 187.

Furu, T. (1992). PhD Thesis, The Norwegian Institute of Technology, Trondheim, Norway. 
Furu, T., Marthinsen, K. and Nes, E. (1993). Materials Science Forum, 113-115, 41.

Hansen, N. and Bay, B. (1981). Acta met., 29, 65.

Hazzledine, P. M., Hirsch, P. B. and Louat, N. (1980). Proc. 1st Risø Int. symposium, (eds. N. Hansen et al.), 159, Roskilde, Denmark.

Herbst, P. and Huber, J. (1978). in "Textures of Materials", Proc. ICOTOM 5, (eds. G. Gottstein and K. Lücke), I, 453, Berlin, Springer-Verlag.

Hillert, M. (1988). Act met., 36, 3177.

Humphreys, F. J. (1977). Acta met., 25, 1323.

Humphreys, F. J . (1979). Acta met., 27, 1801.

Humphreys, F. J. (1980). Proc.1st Risø Int. Symposium, (eds. N. Hansen et al.), 35, Roskilde, Denmark.

Humphreys, F. J. (1987). Kalu, P. N., Acta met., 35, 2815.

Humphreys, F. J. (1994). Ardakani, M. G., Acta met., 42, 749.

Hutchinson, W. B. (1989). Acta met., 37, 1047.

Hutchinson, W. B., Oscarsson, A. and Karlsson, A. (1989). Mat. Sc. Tech., 5, 1118.

Jack, D. B., Koken, E. and Underhill, R. (1989). Proc. 10th Risø Int. symposium, (eds. Bilde-Sørensen et al.,) 403, Roskilde, Denmark.

Juul Jensen, D., Hansen, N. and Liu, Y. L. (1991). Mat. Sc. Tech., 2, 369.

Juul Jensen D., Bolingbroke, R. K., Shi, H., Shahani, R. and Furu, T. (1994). Materials Science Forum, 157-162, 1991.

Leslie, W. C., Michalak, J. T., Aul and F. W. (1963). in "Iron and its Dilute Solid Solutions), (eds. Spencer and Werner), 119, Interscience, New York, 1470.

Liu, X., Solberg, J. K., Gjengedal, R. and Kluken, A. O. (1995). Mat. Sc. Tech., 11, 469.

Lücke, K. and Engler, O. (1992). Proc. ICAA3, (eds. L. Arnberg et al.), III, 439, Norway.

Louat, N. (1983). Phil. Mag., 47, 903.

Nes, E. (1976). Acta met., 24, 391.

Nes, E. (1979). Metal Sci., 13, 211.

Nes, E. and Wert, J. A. (1984). Scripta met., 18, 1433.

Nes, E., Ryum, N. and Hunderi, O. (1985). Acta met., 33, 11.

Nes, E. and Hutchinson, W. B. (1989). Proc.10th Ris $\phi$ Int. Symposium, (eds. J. B. Bilde-Sørensen et al.), 233, Roskilde, Denmark.

Nes, E., Vatne, H. E., Daaland, O., Furu, T., Ørsund, R. and Marthinsen, K. (1994). Proc. ICAA4, (eds. T.H. Sanders Jr. and E.A. Starke), III, 18, Atlanta.

Rabet, L., Ratchev, Verlinden B. and Van Houtte, P. (1995). Proc.16th Ris $\phi$ Int. Symposium, (eds. N. Hansen et al.), 525, Roskilde, Denmark.

Rath, B. B. and Hu, H. (1969). Trans. TMS-AIME, 245, 1243, ibid., 1577.

Ridha, A. A. and Hutchinson, W. B. (1982). Acta met., 30, 1929.

Russel, K. C. and Ashby, M. F. (1970). Acta met., 18, 891.

Samajdar, I. and Doherty, R. D. (1995). Submitted to Acta met.

Silveira, J. M. and Barbosa, R. (1993). Scripta met., 29, 881.

Sircar, S. and Humphreys, F. J. (1994). Proc. ICAA4, (eds. T.H. Sanders Jr. and E.A. Starke), I, 170 , Atlanta.

Skjaervold, S. and Ryum, N. (1996). Acta met., in press.

Smith, C. S., (1948). Trans. metall. Soc. AIME, 175, 15.

Stowell, M. J. (1983). Proc.4th Risø Int. Symposium, (eds. N. Hansen et al.), 531, Roskilde, Denmark.

Strid, J., Furu, T., Ørsund, R. and Nes, E. (1988). Proc. "Continuous Casting of Non-Ferrous Metals and Alloys", (Eds. H.D. Merchant et al.), TMS, Warrendale, Pa.

Strid, J. (1990). unpublished work, Hydro Aluminium, Sunndalsøra.

Vatne, H. E., Hoffman, S., Bardal, A. and Nes, E. (1994a). Proc. ICSMA10, (eds. Oikawa et al.), 255, The Japan Institute of Metals, Sendai.

Vatne, H. E., Engler, O. and Nes, E. (1994b). Materials Science Forum, 157-162, 1501.

Vatne, H. E., Daaland, O. and Nes, E. (1994c). Materials Science Forum, 157-162, 1807.

Vatne, H. E. (1995). PhD Thesis, The Norwegian Institute of Technology, Trondheim, Norway.

Vatne, H. E., Furu, T. and Nes, E. (1995a). Mat. Sc. Tech., in press.

Vatne, H. E., Shahani and R., Nes, E. (1995b). Acta met., in press.

Vatne, H. E., Benum, S., Shahani, R. and Nes, E. (1995c). Proc. 16th Risø Int. Symposium, (eds. N. Hansen et al,). 573, Roskilde, Denmark.

Vatne, H. E., Engler, O. and Nes, E. (1995d). Mat. Sc. Tech., in press.

Vatne, H. E., Furu, T., Ørsund, R. and Nes, E. (1995e). Acta met., in press.

Vatne, H. E. and Nes, E. (1995f). Proc. 16th Risф Int. Symposium, (eds. N. Hansen et al,). 581, Roskilde, Denmark. 
Wassermann, G., Bergmann, H. W. and Fromeyer, G. (1978). in "Textures of Materials", Proc. ICOTOM 5, (eds. G. Gotttstein and K. Lücke), II, 37, Berlin, Springer-Verlag.

Weiland H. (1995). Proc. 16th Risø Int. Symposium, (eds. N. Hansen et al,). 215, Denmark.)

Ørsund, R. and Nes, E. (1988) Scripta met., 22, 671. 